ISSN: 2277-3754

ISO 9001:2008 Certified

International Journal of Engineering and Innovative Technology (IJEIT)

Volume 11, Issue 2, August 2021

\title{
Multi-Critical Water Depths and Precise Discharge Determination for Symmetrically Compound Channel in Unsteady State Flows
}

Edward Ching-Ruey, LUO

Department of Civil Engineering, National Chi-nan University, Nantou, TAIWAN

United States Army Corps of Engineers, HEC-2 1982 [ 8 ];

Abstract-The critical depth, which making unstable flow situation for necessary avoiding on design, of channel flow influences the water-surface profile obviously, and it defines the relationships between specific energy and discharge. Generally speaking, for a given discharge and the shape of cross-section, the minimum specific energy will have the corresponding only one critical depth as the initial condition for computing the steady gradually varied flow. In this paper, we will discuss the situation of critical depths on symmetrically compound channel flows in unsteady state incorporating a general definition of Froude number based on the $1 D$ unsteady momentum and continuity equations with the self-derived $3 D$ velocity profile. With the self-derived velocity profile, the critical depth may be calculated step-by-step and the precise discharge determined and compared. Examples for calculations and comparisons for critical depth and discharge are given and some discussion also presented finally.

Index Terms - Symmetrically compound channel, critical depth, unsteady state gradual flow, Froude number, momentum and continuity equation, velocity profile, discharge.

\section{INTRODUCTION}

With a given single cross section, the specific energy is minimum at the critical depth for a given discharge, meanwhile a given specific energy with the maximum discharge when the flow depth is critical. This is the unique theory for the requirement condition of critical-depth in the simple channel section, but how are the situations of a compound channel flows (Fig. 1)? Is there still only one value of critical depth or more with symmetrically compound channel flow (Fig. 2) if the separated Froude numbers are used for the main-channel and the floodplain respectively (Schoellhamer, D.H. et al.,1985〔5]; Blalock, M.E. et al.,1981 [1] ; Konemann, N.et al., 1982 [2] ; and Petryk, S. et al., 1978 [4] )? What we need to do for the situations with multi-critical depths will be necessary on determining the values to carefully calculate the profiles of water-surface flows. There were several difficulty available methods for computing the corresponding critical depths for compound channels flows by utilization on new Froude number of the entire section (Blalock, M.E. et al.,1981 [ 1 ] ; Petryk, S. et al., 1978 [ 4 ]; Soil Conservation Service, 1976[ 6]; Sturm, T.W. $1985[7]$;

Manuscript received: 23 July 2021

Manuscript received in revised form: 21 August 2021

Manuscript accepted: 4 September 2021

Manuscript Available online: 15 September 2021 and United States Geological Survey, 1976[9]). What are the obvious problems? Is it possible that the flow may be critical with Froude number is equal to one but the specific energy not minimum?.

\section{II.THEORETICAL CONSIDERATION}

For the purpose of determining the possible number of critical depths in a compound channel with a given discharge, the 1D unsteady momentum and continuity equations are used for the defining and presenting the Froude number and the calculation of values of the possible critical depths Accordingly, the only one critical depth is presented for the design needed. As we know, the compound channel flow is in $3 \mathrm{D}$, at least quasi-3D, or said $2 \mathrm{D}$, especially when the water depth is above the main channel, called overbank, is shallow. $\frac{\partial \mathrm{A}}{\partial \mathrm{t}}+\frac{\partial(\mathrm{AV})}{\partial \mathrm{x}}=0$

$\frac{1}{\mathrm{~g}} \frac{\partial \mathrm{V}}{\partial \mathrm{t}}+\frac{\mathrm{V}^{2}}{\mathrm{~g}} \frac{\partial \beta}{\partial \mathrm{x}}+(2 \beta-1) \frac{\mathrm{V}}{\mathrm{g}} \frac{\partial \mathrm{V}}{\partial \mathrm{x}}+(\beta-1) \frac{\mathrm{V}^{2}}{\mathrm{~g}} \frac{1}{\mathrm{~A}} \frac{\partial \mathrm{A}}{\partial \mathrm{x}}=\mathrm{S}_{0}-\mathrm{S}_{\mathrm{f}}$

In which $\mathrm{A}=$ area of cross section; $\mathrm{V}=$ mean flow velocity for the given cross-section; $\mathrm{g}=$ gravity acceleration; $\beta=$ correction coefficient of momentum; $\mathrm{S} 0=$ channel bottom slope; $\mathrm{Sf}=$ slope of energy grade slope; and $\mathrm{x}$, and $\mathrm{t}=$ distance and time coordinate respectively. For the assumption of small bed bottom slope and hydrostatic pressure, S0 and Sf are negligible. The equation of flow characteristics by combining Eqs. (1) and (2) is:

$\frac{\mathrm{dx}}{\mathrm{dt}}=\beta \mathrm{V} \pm \sqrt{\frac{\mathrm{gA}}{\mathrm{B}}+\mathrm{V}^{2}\left(\beta^{2}-\beta+\frac{\mathrm{A} \beta^{\prime}}{\mathrm{B}}\right)}$

$B=$ the water surface width, $\beta^{\prime}=d \beta / d Z$, and $Z$ =flow depth, $\mathrm{dx} / \mathrm{dt}$ is the characteristic direction in the $\mathrm{x}-\mathrm{t}$ plane. The positive sign, the first item on right- hand side greater than the second item, is for downstream direction while for upstream with negative sign. $\mathrm{dx} / \mathrm{dt}$ is for both directions if $\mathrm{dx} / \mathrm{dt}$ is positive with the supercritical flow to downstream direction. When $\mathrm{dx} / \mathrm{dt}$ is negative, the first item on right- hand side smaller than the second item, for the upstream direction, and positive for downstream direction, the subcritical flows exist. For critical flow, the ratio between the first and second items of right-hand side in Eq. (3) is equal to 1. The total section Froude number is defined as: 


\section{|UEGT}

ISSN: 2277-3754

ISO 9001:2008 Certified

International Journal of Engineering and Innovative Technology (IJEIT)

Volume 11, Issue 2, August 2021

$$
F_{c}=\frac{\beta V}{\sqrt{\frac{g A}{B}+V^{2}\left(\beta^{2}-\beta+\frac{A \beta^{\prime}}{B}\right)}}
$$

Where: if $F_{c}=1$, then

$\frac{\mathrm{g}}{\mathrm{Q}^{2}}=\frac{\beta \mathrm{B}-\mathrm{A} \beta^{\prime}}{\mathrm{A}^{3}}$

$\beta=\frac{\sum_{\mathrm{i}} \frac{\mathrm{K}_{\mathrm{i}}^{2}}{\mathrm{~A}_{\mathrm{i}}} \mathrm{A}}{\mathrm{K}^{2}} \mathrm{~A}$

$\mathrm{E}=\mathrm{Z}+\frac{\alpha \mathrm{Q}^{2}}{2 \mathrm{gA}^{2}}$

$\alpha=\frac{\sum_{\mathrm{i}} \mathrm{K}_{\mathrm{i}}^{3}}{\mathrm{~A}_{\mathrm{i}}^{2}} \mathrm{~A}^{2}$

$\mathrm{K}_{\mathrm{i}}=\frac{1}{\mathrm{n}_{\mathrm{i}}} \mathrm{A}_{\mathrm{i}} \mathrm{R}_{\mathrm{i}}^{2 / 3}$

$\mathrm{Q}=$ discharge, and $\mathrm{K}=$ conveyance $=\Sigma \mathrm{Ki}$, the subscript "i" denotes the variables for the $i$-th subsection, $\mathrm{n}=$ Manning coefficient, $\mathrm{R}=$ hydraulic radius $=\mathrm{A} / \mathrm{P}$, and $\mathrm{P}=$ wetted perimeter.

By substituting Eqs. (6) znd (9) into Eq. (5), and letting the:

$\frac{\mathrm{K}_{1}}{\mathrm{~K}_{1}+2 \mathrm{~K}_{2}}=\mathrm{m}$

or $\mathrm{m}=\frac{1}{1+2 \mathrm{n}_{\mathrm{s}}\left(\frac{\mathrm{A}_{2}}{\mathrm{~A}_{1}}\right)^{5 / 3}\left(\frac{\mathrm{P}_{1}}{\mathrm{P}_{2}}\right)^{2 / 3}}$

and $\mathrm{ns}=\mathrm{nm} / \mathrm{nf}=1 / \mathrm{nr}$.

then we obtain

$\beta=\left(\frac{K_{1}^{2}}{A_{1}}+\frac{2 K_{2}^{2}}{A_{2}}\right) \frac{A}{\left(K_{1}+2 K_{2}\right)^{2}}$

or $\beta=\left(\frac{m^{2}}{A_{1}}+\frac{(1-m)^{2}}{2 A_{2}}\right) A$

with $\frac{\mathrm{g}}{\mathrm{Q}^{2}}=\frac{\mathrm{B}}{\mathrm{A}^{2}}\left\{\frac{\mathrm{m}^{2}}{\mathrm{~A}_{1}}+\frac{(1-\mathrm{m})^{2}}{2 \mathrm{~A}_{2}}\right\}-\frac{\beta^{\prime}}{\mathrm{A}^{2}}$

$\beta^{\prime}=B\left\{\frac{m^{2}}{A_{1}}+\frac{(1-m)^{2}}{2 A_{2}}\right\}+2 A\left\{\frac{m}{A_{1}}-\frac{(1-m)}{2 A_{2}}\right\} \frac{d m}{d Z}$

$-\mathrm{A}\left\{\left(\frac{\mathrm{m}}{\mathrm{A}_{1}}\right)^{2} \frac{\mathrm{dA}_{1}}{\mathrm{dZ}}+\frac{(1-\mathrm{m})^{2}}{2 \mathrm{~A}_{2}^{2}} \frac{\mathrm{dA_{2 }}}{\mathrm{dZ}}\right\}$

where

$\frac{\mathrm{dm}}{\mathrm{dZ}}=\frac{\mathrm{d}}{\mathrm{dZ}}\left(\frac{\mathrm{K}_{1}}{\mathrm{~K}_{1}+2 \mathrm{~K}_{2}}\right)=\frac{2}{\left(\mathrm{~K}_{1}+2 \mathrm{~K}_{2}\right)^{2}}\left(\mathrm{~K}_{2} \frac{\mathrm{dK}_{1}}{\mathrm{dz}}-\mathrm{K}_{1} \frac{\mathrm{dK}_{2}}{\mathrm{dz}}\right)$

or $\frac{\mathrm{dm}}{\mathrm{dz}}=2\left(\frac{\mathrm{K}_{2}}{\mathrm{~K}}\right)^{2} \frac{\mathrm{d}}{\mathrm{dz}}\left(\frac{\mathrm{K}_{1}}{\mathrm{~K}_{2}}\right)$

and

$\frac{\mathrm{d}}{\mathrm{dZ}}\left(\frac{\mathrm{K}_{1}}{\mathrm{~K}_{2}}\right)=\frac{5 \mathrm{~K}_{1}}{3 \mathrm{~K}_{2}}\left(\frac{1}{\mathrm{~A}_{1}} \frac{\mathrm{dA}_{1}}{\mathrm{dZ}}-\frac{1}{\mathrm{~A}_{2}} \frac{\mathrm{dA}_{2}}{\mathrm{dZ}}\right)+\frac{2 \mathrm{~K}_{1}}{3 \mathrm{~K}_{2}} \frac{1}{\mathrm{P}_{2}} \frac{\mathrm{dP}_{2}}{\mathrm{dZ}}$

therefore,

$\frac{\mathrm{dm}}{\mathrm{dZ}}=\mathrm{m}(1-\mathrm{m})\left\{\frac{5}{3}\left(\frac{1}{\mathrm{~A}_{1}} \frac{\mathrm{dA}_{1}}{\mathrm{dZ}}-\frac{1}{\mathrm{~A}_{2}} \frac{\mathrm{dA}_{2}}{\mathrm{dZ}}\right)+\frac{2}{3} \frac{1}{\mathrm{P}_{2}} \frac{\mathrm{dP}_{2}}{\mathrm{dZ}}\right\}$

Finally, the Eq. (5) becomes:

$\frac{\mathrm{gA}}{\mathrm{Q}^{2}}=\left(\frac{\mathrm{m}}{\mathrm{A}_{1}}\right)^{2} \frac{\mathrm{dA}_{1}}{\mathrm{dz}}+\frac{1}{2}\left(\frac{1-\mathrm{m}}{\mathrm{A}_{2}}\right)^{2} \frac{\mathrm{dA}_{2}}{\mathrm{dz}}-2 \mathrm{~m}(1-\mathrm{m})\left\{\frac{5}{3}\left(\frac{1}{\mathrm{~A}_{1}} \frac{\mathrm{dA}_{1}}{\mathrm{dz}}-\right.\right.$

$\left.\left.\frac{1}{\mathrm{~A}_{2}} \frac{\mathrm{dA}_{2}}{\mathrm{dz}}\right)+\frac{2}{3} \frac{1}{\mathrm{P}_{2}} \frac{\mathrm{dP}_{2}}{\mathrm{dz}}\right\}\left\{\frac{\mathrm{m}}{\mathrm{A}_{1}}-\frac{(1-\mathrm{m})}{2 \mathrm{~A}_{2}}\right\}$
For the convenience of calculation, some symbols are defined as following:

$\mathrm{z}=\frac{\mathrm{Z}}{\mathrm{Z}_{\mathrm{m}}}=\frac{\mathrm{Z}}{\mathrm{Z}-\mathrm{d}}=\frac{\mathrm{D}}{\mathrm{D}-\mathrm{d}}$

$b_{r}=\frac{B_{f}}{B_{m}}=\left(\frac{b}{2}-\frac{B}{2}\right) /\left(\frac{B}{2}\right)$

$\mathrm{b}_{\mathrm{f}}=\frac{\mathrm{B}_{\mathrm{f}}}{\mathrm{Z}_{\mathrm{m}}}=\frac{\frac{\mathrm{b}}{2}-\frac{\mathrm{B}}{2}}{\mathrm{D}-\mathrm{d}}$

$\mathrm{b}_{\mathrm{m}}=\frac{\mathrm{B}_{\mathrm{m}}}{\mathrm{Z}_{\mathrm{m}}}=\left(\frac{\mathrm{B}}{2}\right) /(\mathrm{D}-\mathrm{d})$

$\mathrm{C}_{1}=\frac{\mathrm{dA}_{2}}{\mathrm{dZ}} / \frac{\mathrm{dA}_{1}}{\mathrm{dZ}}$

$\mathrm{C}_{2}=\frac{\mathrm{A}_{1}}{\mathrm{~A}_{2}}$

$\mathrm{C}_{3}=\frac{\mathrm{A}_{1}}{\mathrm{P}_{2}} \frac{\mathrm{dA}_{2}}{\mathrm{dZ}} / \frac{\mathrm{dA}_{1}}{\mathrm{dZ}}$

$\frac{\mathrm{gB}_{\mathrm{m}}^{2} \mathrm{Z}_{\mathrm{m}}^{3}}{\mathrm{Q}^{2}}=\mathrm{C}$

or

$C\left\{1+\frac{B_{f m} Z_{m}}{A_{m}}(Z-1)\right\}^{3}=\frac{C_{2}}{1+C_{2}}\left\{m^{2}+\frac{1}{2}(1-m)^{2} C_{1} C_{2}^{2}\right\}-$ $\frac{2 \mathrm{~m}(1-\mathrm{m}) \mathrm{C}_{2}}{3\left(1+\mathrm{C}_{2}\right)} \times\left\{5\left(1-\mathrm{C}_{1} \mathrm{C}_{2}\right)+2 \mathrm{C}_{3}\right\}\left\{\mathrm{m}-\frac{1}{2}(1-\mathrm{m}) \mathrm{C}_{2}\right\}$

$\mathrm{Z}_{\mathrm{c}}=\left(\frac{\mathrm{Q}^{2}}{\mathrm{gB}_{\mathrm{m}}^{2}}\right)^{1 / 3}$

The compound channel is vertically divided into one main channel with the footnote 1 , while the footnote 2 for the two floodplains. The footnote "f" is for floodplain and the other footnote " $\mathrm{m}$ " is for main channel. " $\mathrm{D}$ " (or Z) is the water depth of main channel and "d" the one of floodplain. "b" is the total width of the compound channel section, and " $\mathrm{B}$ " the one of main channel.

For the symmetrical compound channel section, we have:

$\mathrm{C}_{1}=\frac{\mathrm{B}_{\mathrm{f}}}{\mathrm{B}_{\mathrm{m}}}=\mathrm{b}_{\mathrm{r}}$

$C_{2}=\frac{B_{m} Z}{B_{r}\left(Z-Z_{m}\right)}=\frac{z}{(z-1) b_{r}}$

$\mathrm{C}_{3}=\frac{\mathrm{z}}{\mathrm{b}_{\mathrm{f}}+\mathrm{z}-1}$

and

$C=\frac{1}{z+2 b_{r}(z-1)}\left[\left\{\left(\frac{m}{z}\right)^{2}+\left(\frac{1-m}{z-1}\right)^{2} \frac{1}{2 b_{r}}\right\}\right.$

$\left.+\frac{2 \mathrm{~m}(1-\mathrm{m})}{3\left(\mathrm{z}+2 \mathrm{~b}_{\mathrm{r}}(\mathrm{z}-1)\right)}\left\{\frac{5}{\mathrm{z}(\mathrm{z}-1)}-\frac{2}{\mathrm{~b}_{\mathrm{f}}+\mathrm{z}-1}\right\}\left\{\left(\frac{\mathrm{m}}{\mathrm{z}}\right)-\left(\frac{1-\mathrm{m}}{\mathrm{z}-1}\right) \frac{1}{2 \mathrm{~b}_{\mathrm{r}}}\right\}\right]$

In Eq. (31),C is a function of $z, n s, b_{r}$, and $b_{f}$. The $C-z$ relationship curve may be plotted for determining the critical depth with a given discharge and a known compound channel section. The symbols from Eq. (10) to Eq. (31) could be referenced in Figs. 2 and 3. The s1 and s2 are the side slopes for the trapezoid cross-section. Additionally, we need note 
ISSN: 2277-3754

\section{ISO 9001:2008 Certified \\ International Journal of Engineering and Innovative Technology (IJEIT) \\ Volume 11, Issue 2, August 2021}

that the dotted lines in the figures are not included for the wetted perimeter. The relationship between $\mathrm{Cmax}$ and bf for the given roughness ratio is shown in Fig. 4 to presenting the variation of $\mathrm{br}$ and $\mathrm{bm}$, meanwhile the relationship between $\mathrm{Cmax}$ and bf for the given width ratio with the variation of roughness ratio is shown in Fig. 5. There is one question that the turbulent shear stress on the position really zero? Is the discharge influenced when we neglect these wetted perimeter?

\section{III.SELF-DERIVED PRIMARY VELOCITY PROFILE}

Luo (1993) [3] derived a set of velocity profile equations for both the center and the cross-section of symmetric compound channels.

\section{A. Primary velocity profile at the centerline $U_{C L}(z)$ :}

$$
U_{C L} / U_{C L M}=\operatorname{Exp}\left[-0.71\left(\frac{z}{D}-0.65\right)^{2}\right]
$$

where $\mathrm{U}_{\mathrm{CLM}}$ is the maximum velocity in the centerline of compound channel, and

B. Velocity profiles of primary flow to their corresponding horizontal-plane position $U(y . z)$ :

$$
\begin{aligned}
& U(y, z)=1.177\left(D_{r}\right)^{0.2004}\left(n_{r}\right)^{-0.2300} \\
& \left(\frac{Y}{b / 2}\right)^{0.2545}\left(\frac{z}{D}\right)^{-0.3536} U_{C L}\left(y, z_{c}\right)
\end{aligned}
$$

The schemes of the symbols are shown in Fig. 2. Therefore, mean velocity for the whole cross-section could be obtained by double integral for both lateral y from the left to the right boundaries, and vertical $\mathrm{z}$ from channel bottom to the water surface then divided by the total area of given cross-section. Of course, the mean velocities of the partially corresponding areas, berm or called floodplain and main channel also might be solved on the same procedures with just modifying the boundary conditions and the nr values. From Eqs. (32) and (33), then we have:

$$
\begin{gathered}
\mathrm{U}=13.85\left(D_{r}\right)^{0.2004}\left(n_{r}\right)^{-0.2300}\left[{ }^{y} /(b)\right]^{0.2545} \\
(Z / D)^{-0.3556} \operatorname{Exp}\left[-0.71\left(\frac{z}{D}-0.65\right)^{2}\right] U_{C L M}
\end{gathered}
$$

Bysetting

$$
\begin{aligned}
& t^{2}=0.71\left(\frac{Z}{D}-0.65\right)^{2} \\
& (Z / D)^{-0.3556}=f(a)+\sum_{k=1}^{n}\left(f^{k}(a) / k !\right)\left(\frac{Z}{D}-a\right)^{k}, \mathrm{a}=0.65 \\
& =1.1655+0.6376\left(\frac{Z}{D}-0.65\right)-0.6649\left(\frac{Z}{D}-0.65\right)^{2} \\
& -0.8032\left(\frac{Z}{D}-0.65\right)^{3}+1.0366\left(\frac{Z}{D}-0.65\right)^{4}+ \\
& =1.1655+0.7563 t-0.9356 t^{2}-1.3407 t^{3}+2.0526 t^{4} \text {. } \\
& \text { with } \mathrm{t}=0.843\left(\frac{Z}{D}-0.65\right) \text { and } \\
& \operatorname{Exp}\left[-0.71\left(\frac{Z}{D}-0.65\right)^{2}\right]=\exp \left[-t^{2}\right]
\end{aligned}
$$

Therefore we have,

$$
\begin{aligned}
& \mathrm{U} 13.85\left(D_{r}\right)^{0.2004}\left(n_{r}\right)^{-0.2300}\left[y^{y} /(b)\right]^{0.2545} \exp \left[-t^{2}\right] U_{C L M} \\
& \left.1.1655+0.7563 t-0.9356 t^{2}-1.3407 t^{3}+2.0526 t^{4} \ldots\right\} \text {..(37) } \\
& \bar{U}=\left(\frac{1}{b D}\right) \int_{y} \int_{z} U d z d y=\left(\frac{1}{b}\right) \int_{y} \int_{z^{*}} U d z^{*} d y \text {. } \\
& =11.04\left(D_{r}\right)^{0.2004} U_{C L M}\left(n_{r}\right)^{-0.2300}(y / b)^{1.2545} \mathrm{I}_{y_{1 *}}^{y_{2 *}}\{ \\
& 0.5828(\sqrt{\pi})\left(\operatorname{erf}_{2}-\operatorname{erf} t_{1}\right)+0.0500\left(e^{-t_{1}^{2}}-e^{-t_{2}^{2}}\right)-2.0070 \\
& \left(t_{1} e^{-t_{1}^{2}}-t_{2} e^{-t_{2}^{2}}\right)-0.6704\left(t_{1}^{2} e^{-t_{1}^{2}}-t_{2}^{2} e^{-t_{2}^{2}}\right)+1.0263( \\
& \left.\left.t_{1}^{3} e^{-t_{1}^{2}}-t_{2}^{3} e^{-t_{2}^{2}}\right)+\ldots \ldots .\right\} \quad \ldots \ldots \ldots \ldots \ldots \ldots \ldots \ldots \ldots . . .(39) \\
& U^{\prime}=\mathrm{U}-\bar{U}=\left(D_{r}\right)^{0.2004}\left(n_{r}\right)^{-0.2300} U_{C L M}\left\{13.85\left[{ }^{y} /(b)\right]^{0.2545}\right.
\end{aligned}
$$$$
\left[1.1655+0.7563 t-0.9356 t^{2}-1.3407 t^{3}+2.0526 t^{4} \ldots\right]
$$$$
\exp \left[-t^{2}\right]_{-}^{11.04\left[{ }^{y} /(b)\right]^{1.2545}} \mathrm{I}_{y_{1^{*}}}^{y_{2^{*}}}\left[0 . 5 8 2 8 ( \sqrt { \pi } ) \left(\operatorname{erf} t_{2^{-}}\right.\right.
$$$$
\left.\operatorname{erf} t_{1}\right)+0.0500\left(e^{-t_{1}^{2}}-e^{-t_{2}^{2}}\right)-2.0070\left(t_{1} e^{-t_{1}^{2}}-t_{2} e^{-t_{2}^{2}}\right)
$$$$
-0.6704\left(t_{1}^{2} e^{-t_{1}^{2}}-t_{2}^{2} e^{-t_{2}^{2}}\right)+1.0263\left(t_{1}^{3} e^{-t_{1}^{2}}-t_{2}^{3} e^{-t_{2}^{2}}\right)
$$$$
+\ldots . . .] \text { \} }
$$

and

$$
\begin{aligned}
& D_{y}=U^{\prime}(y) \int_{0}^{y}\left(1 / v_{t y}\right) \int_{0}^{y} U^{\prime}(\mathrm{y}) \mathrm{dydy}=\mathrm{f}(\mathrm{z}) \text {. } \\
& \overline{D_{y}}=\left(-1 / B_{e}\right) \int_{0}^{B_{e}} D_{y} \mathrm{dy} \text {... }
\end{aligned}
$$

\section{IV.STEPS ON CRITICAL DEPTH DETERMINATION}

The procedure of the solutions on Eqs. (25) and (31) on determining the critical depth could be presented as the following example for $\mathrm{Bm}=2 \mathrm{~m}, \mathrm{Bf}=6.0 \mathrm{~m}, \mathrm{Zm}=3.0 \mathrm{~m}$, and $\mathrm{ns}=0.9$. The $\mathrm{C}-\mathrm{z}$ curve for the given compound cross-section as in Fig. 6. When $\mathrm{z} \rightarrow 1, \mathrm{~m} \rightarrow 1$, and $\mathrm{C} \rightarrow 1$, while $\mathrm{z} \rightarrow \infty, \mathrm{m} \rightarrow 0$, $\mathrm{C} \rightarrow 0$. And the curve has $\mathrm{Cmax}$ or say $\mathrm{C}^{*}=2.92$ with the corresponding $\mathrm{z}=1.035$. depending on the valve of $\mathrm{Q}$ in Eq. (27), we illustrate three typically probable situations for describing the reasons on multiple critical depths. The corresponding Froude number, $\left.F_{r}=\bar{U} / \sqrt{g\left({ }^{A} / T\right.}\right)$ where T $=B_{m}$ or $\mathrm{T}=2 B_{f}+B_{m}$, and Reynold number, $R_{e}=\bar{U} \mathrm{R} / v$ with $\mathrm{R}=\mathrm{A} / \mathrm{P}$, and $v=10^{-6} \mathrm{~m}^{2} / \mathrm{s}$.

1. $\mathrm{Q}=17.0 \mathrm{cms}$, in Eq. (25), $\mathrm{C}=3.67$ with no intersection with $\mathrm{C}$-z curve meaning no critical depth, $\mathrm{Zc}$, happening in the situation of $Z>Z m$ in Fig. 6. Here Zc1 are obtained in Eq. (27), of $1.945 \mathrm{~m}$, and $\bar{U}_{c}=4.37 \mathrm{~m} / \mathrm{s}$. It means there is only one critical depth for this case. $F_{r}=1$ and $R_{e}=2.886 \times 10^{6}$.

2. $\mathrm{Q}=25.0 \mathrm{cms}$, in Eq. (25), $\mathrm{C}=1.69$ with $\mathrm{z} 2=1.01$, and $\mathrm{Z} 3=1.12$, or said, $\mathrm{Zc} 2=1.01 \mathrm{Zm}=3.03 \mathrm{~m}, \mathrm{Zc} 3=1.12 \mathrm{Zm}=3.36 \mathrm{~m}$. Here $\mathrm{Zc} 1=2.516$ are obtained in Eq. (27). Three critical depths happen for this situation. Here, we have $\overline{U_{c 1}}=4.97 \mathrm{~m} / \mathrm{s}$, $\overline{U_{c 2}}=3.89 \mathrm{~m} / \mathrm{s}$, and $\overline{U_{c 3}}=2.26 \mathrm{~m} / \mathrm{s}$ with $S_{c 2}>S_{c 1}>S_{c 3}$ and $S_{c 1}=0.0076, S_{c 2}=0.0159$, and $S_{c 3}=0.00272$. In these case, the water surface profiles for the normal depth and critical depth, corresponding to the bed slope and critical energy slopes, are given as the example in Fig. 7. $F_{r 1}=F_{r 2}=F_{r 3}=1$, 
ISSN: 2277-3754

\section{ISO 9001:2008 Certified \\ International Journal of Engineering and Innovative Technology (IJEIT) \\ Volume 11, Issue 2, August 2021}

and $R_{e 1}=3.556 \times 10^{6}, R_{e 2}=1.245 \times 10^{6}, R_{e 3}=1.204 \times 10^{6}$.

3. $\mathrm{Q}=35.0 \mathrm{cms}$, in Eq. (25), $\mathrm{C}=0.86$ with $\mathrm{z} 2=1.17$, or said, $\mathrm{Zc} 2=1.17 \mathrm{Zm}=3.51 \mathrm{~m}$. Here $\mathrm{Zc} 1=3.149$ are obtained in Eq. (27). Two critical depths, $\mathrm{Zc} 1$ and $\mathrm{Zc} 2$ are obtained here. $\overline{U_{c 1}}$ $=4.33 \mathrm{~m} / \mathrm{s}$ and $\overline{U_{c 2}}=2.66 \mathrm{~m} / \mathrm{s} . S_{c 1}=0.0148$ and $S_{c 2}=0.0031$, that is, $S_{c 1}>S_{c 2} . F_{r 1}=F_{r 2}=1$, and $R_{e 1}=1.725 \times 10^{6}, R_{e 2}=1.663 \times 10^{6}$.

One obvious concept we should pay attention is that the critical slope condition, which could be solved with Manning equation, is unstable and is needed avoiding for designing. In Eqs. (10-1) and (31), and Fig. 7, there we find that for a given $\mathrm{bf}$, the Cmax increases with increasing of $\mathrm{ns}$ or with decreasing of $\mathrm{nr}$ and this phenomenon gives an important information that the variation of the roughness ratio on the vertical division for main channel and floodplain will cause the influence on momentum transfer and affecting the mass flux transfer at the same time.

Based on the definition of Fig. 2. and Luo (2011), the effects of roughness ratio, $\mathrm{nf} / \mathrm{nc}$, presenting the roughness difference between main-channel and floodplain, will affect the turbulent viscosity (Figs. 8 and 9) which is the main factor for turbulent shear stress. By combination of depth ratio, $d / D$, and roughness ratio (Luo, 2011) 〔 10] the apparent shear stress, difference on the momentum transfer at the vertical intersection, treated as perimeter, between main-channel and floodplain, will obviously affect the precision of the mass flux transfer, which will cause the error of discharge calculation.

\section{SUB-CHANNEL VELOCITIES CALCULATION AND DISCHARGE COMPARISONS}

Based on the results of Eqs. (34) and (39), we have the 2D velocity profile equation with its mean velocity distribution profile for separately calculating the discharge of each section and, by the way, comparing the precise for different methods on channel section cutting. Luo (2011) [10] expressed the apparent shear stress for the vertical intersection of the edge on floodplain influencing the momentum and mass flux transferring and the larger is the $\mathrm{d} / \mathrm{D}$, the more precise the discharge, or mass flux (Figs. 10 and 11).

In turbulent flow, the turbulent shear stress owns some characteristics, $\tau_{x z}=v_{t z}(\partial u / \partial z)>\tau_{x y}=v_{t y}(\partial v / \partial y)$, $\partial u / \partial z>\partial v / \partial y$, and $v_{t z} \geqq v_{t y}$, and with of those, the consideration of reducing the error of discharge calculation, the horizontal division (the cutting line $\overline{i j}$ ) for compound channel will be the more suitable situation (Fig. 2). By using Eqs. (38) and (39), and the $\overline{i j}$ is not included as the wet perimeters, then we have:

1. $\mathrm{Q}=25.0 \mathrm{cms}, \mathrm{Zc} 2=3.03 \mathrm{~m}, U_{C L M}=4.4705 \mathrm{~m} / \mathrm{s}, \mathrm{d} / \mathrm{D}=0.01$. Main channel (below $\overline{i j}$ ), $\overline{U_{1}}=4.1817 \mathrm{~m} / \mathrm{s}$, the normal depth slope $S_{n d 1}=0.0051$, and floodplain (above $\overline{i j}$ ), results as $\overline{U_{2}}=-0.2161 \mathrm{~m} / \mathrm{s}$, the normal depth slope, $S_{n u 1}=-0.0011$, and $S_{n u 1}<S_{n d 1}<S_{c 2}=0.0159$. The sign presents the variation of velocity from positive value to negative one at the line $\overline{i j}$ with significant momentum transferring along the cutting line. The difference due to energy slope will cause the stronger eddy or circulation in xy-plane. $F_{\text {rnu } 1}=0.398$, $R_{\text {enu } 1}=7,526 ; F_{\text {rnd } 1}=0.771, R_{\text {end } 1}=3.136 \times 10^{6}$.

2. $\mathrm{Q}=25.0 \mathrm{cms}, \mathrm{Zc} 3=3.36 \mathrm{~m}, U_{C L M}=5.2169 \mathrm{~m} / \mathrm{s}, \mathrm{d} / \mathrm{D}=0.11$. Main channel (below $\overline{i j}$ ), $\overline{U_{1}}=3.6764 \mathrm{~m} / \mathrm{s}, S_{n d 1}=0.0039$, and floodplain (above $\overline{i j}$ ), $\overline{U_{2}}=0.5877 \mathrm{~m} / \mathrm{s}, S_{n u 1}=0.0003$, and $S_{n u 1}<S_{c 3}=0.00272<S_{n d 1}$. Because the same signs of velocity in both sub-channels, there has shear stress (or says momentum transferring), but without eddy or circulation in xy-plane. $F_{\text {rnu } 1}=0.313, R_{\text {enu } 1}=2.329 \times 10^{5} ; F_{\text {rnd } 1}=0.678$, $R_{\text {end } 1}=2.757 \times 10^{6}$.

3. $\mathrm{Q}=35.0 \mathrm{cms}, \mathrm{Zc} 2=3.51 \mathrm{~m}, U_{C L M}=4.6593 \mathrm{~m} / \mathrm{s}, \mathrm{d} / \mathrm{D}=0.15$. Main channel (below $\overline{i j}$ ), $\overline{U_{1}}=4.0806 \mathrm{~m} / \mathrm{s}, S_{n d 1}=0.0048$, and floodplain (above $\overline{i j}$ ), $\overline{U_{2}}=1.4729 \mathrm{~m} / \mathrm{s}, S_{n u 1}=0.0013$, and $S_{n u 1}<S_{c 2}=0.0031<S_{n d 1}$. Dut to the same signs of velocity in these two sur-channels, there has shear stress (or says momentum transferring), but without eddy or circulation in xy-plane. $F_{\text {rnu } 1}=0.658, R_{\text {enu } 1}=8.077 \times 10^{5} ; F_{\text {rnd } 1}=0.752$, $R_{\text {end } 1}=3.060 \times 10^{6}$.

If the $\overline{i j}$ is included as the wet perimeters, the Froude number for each case with whether on not $\overline{i j}$ as boundary is not varied, but Reynold number is. Then we have:

4. $\mathrm{Q}=25.0 \mathrm{cms}, \mathrm{Zc} 2=3.03 \mathrm{~m}, U_{C L M}=4.4705 \mathrm{~m} / \mathrm{s}, \mathrm{d} / \mathrm{D}=0.01$. Main channel (below $\overline{i j}$ ), $\overline{U_{1}}=4.1817 \mathrm{~m} / \mathrm{s}, S_{n d 1 *}=0.0068$, and floodplain (above $\overline{i j}$ ), $\overline{U_{2}}=-0.2161 \mathrm{~m} / \mathrm{s}$, and $S_{n u 1 *}=-0.0013$, and $S_{n u 1 *}<S_{n d 1 *}<S_{c 2}=0.0159$. The sign presents the variation of velocity from positive value to negative one at the line $\overline{i j}$ with significant momentum transferring along the cutting line. Of course, the difference due to energy slope will cause the stronger eddy or circulation in xy-plane. $R_{\text {enu } 1}=6,469$ and $R_{\text {end } 1}=2.509 \times 10^{6}$.

5. $\mathrm{Q}=25.0 \mathrm{cms}, \mathrm{Zc} 3=3.36 \mathrm{~m}, U_{C L M}=5.2169 \mathrm{~m} / \mathrm{s}, \mathrm{d} / \mathrm{D}=0.11$. Main channel (below $\overline{i j}$ ), $\overline{U_{1}}=3.6764 \mathrm{~m} / \mathrm{s}, S_{n d 1 *}=0.0052$, and floodplain (above $\overline{i j}$ ), $\overline{U_{2}}=0.5877 \mathrm{~m} / \mathrm{s}, S_{n u 1 *}=0.0004$, and $S_{n u 1 *}<S_{c 3}=0.00272<S_{n d 1 *}$. Because the same signs of velocity in both sub-channels, there has shear stress (or says momentum transferring), but without eddy or circulation in xy-plane. $R_{\text {enu } 1}=2.012 \times 10^{5}$ and $R_{\text {end } 1}=2.206 \times 10^{6}$.

6. $\mathrm{Q}=35.0 \mathrm{cms}, \mathrm{Zc} 2=3.51 \mathrm{~m}, U_{C L M}=4.6593 \mathrm{~m} / \mathrm{s}, \mathrm{d} / \mathrm{D}=0.15$. Main channel (below $\overline{i j}$ ), $\overline{U_{1}}=4.0806 \mathrm{~m} / \mathrm{s}, S_{n d 1 *}=0.0065$, and floodplain (above $\overline{i j}$ ), $\overline{U_{2}}=1.4729 \mathrm{~m} / \mathrm{s}, S_{n u 1 *}=0.0015$, and $S_{n u 1 *}<S_{c 2}=0.0031<S_{n d 1 *}$. Dut to the same signs of velocity in these two sur-channels, there has shear stress (or says momentum transferring), but without eddy or circulation in xy-plane. $R_{\text {enu } 1}=7.002 \times 10^{5}$ and $R_{\text {end } 1}=2.448 \times 10^{6}$.

If the vertical cutting as Figs. (2) and (3), one main-channels with two floodplain are formed. And if we take into account the dot lines as wet perimeters, there are:

7. $\mathrm{Q}=25.0 \mathrm{cms}$ is known, $\mathrm{Zc} 2=3.03 \mathrm{~m}, U_{C L M}=4.4705 \mathrm{~m} / \mathrm{s}$, $\mathrm{d} / \mathrm{D}=0.01$. Main channel, $\overline{U_{1}}=4.1817 \mathrm{~m} / \mathrm{s}$, nm.c. $=0.014$, and floodplain, $\overline{U_{2}}=-0.2161 \mathrm{~m} / \mathrm{s}$, nf.p. $=0.016$. and the normal depth slope, $S_{m . c .}=0.0050, S_{\text {f.p. }}=-0.0013$, and $S_{f . p .}<S_{m . c .}<$ $S_{c 2}=0.0159$. The calculated discharge is $25.26 \mathrm{cms}$ with 1.04 
ISSN: 2277-3754

\section{ISO 9001:2008 Certified \\ International Journal of Engineering and Innovative Technology (IJEIT) \\ Volume 11, Issue 2, August 2021}

$\%$ increment. The sign presents the variation of velocity from positive value to negative one at the vertical dot line with significant momentum transferring along the cutting line. Of course, the difference due to energy slope will cause the stronger eddy or circulation in xy-plane. $F_{r f p}=0.3983$,

$F_{r m c}=0.7670, R_{e f p}=6,419$, and $R_{e m c}=3.1441 \times 10^{6}$.

8. $\mathrm{Q}=25.0 \mathrm{cms}$ is known, $\mathrm{Zc} 2=3.36 \mathrm{~m}, U_{C L M}=5.2169 \mathrm{~m} / \mathrm{s}$, $\mathrm{d} / \mathrm{D}=0.11$. Main channel, $\overline{U_{1}}=3.6764 \mathrm{~m} / \mathrm{s}$, nm.c. $=0.014$, and floodplain, $\overline{U_{2}}=0.5877 \mathrm{~m} / \mathrm{s}$, nf.p. $=0.016$. and the normal depth slope, $S_{m . c .}=0.0037, \quad S_{f . p .}=0.0004$, and $S_{\text {f.p. }}<$ $S_{c 3}=0.00272<S_{m . c .}$. The calculated discharge is $27.24 \mathrm{cms}$ with $8.96 \%$ increment. The sign presents the variation of velocity from positive value to negative one at the vertical dot line with significant momentum transferring along the cutting line. Of course, the difference due to energy slope will cause the stronger eddy or circulation in xy-plane. $F_{r f p}=0.3127$, $F_{r m c}=0.6404, R_{e f p}=1.889 \times 10^{5}$, and $R_{e m c}=2.8331 \times 10^{6}$. 9. $\mathrm{Q}=35.0 \mathrm{cms}$ is known, $\mathrm{Zc2}=3.51 \mathrm{~m}, U_{C L M}=4.6593 \mathrm{~m} / \mathrm{s}$, $\mathrm{d} / \mathrm{D}=0.15$. Main channel, $\overline{U_{1}}=4.0806 \mathrm{~m} / \mathrm{s}, \mathrm{nm} . \mathrm{c} .=0.014$, $S_{m . c .}=0.0046$, and floodplain, $\overline{U_{2}}=1.4729 \mathrm{~m} / \mathrm{s}$, nf.p. $=0.016$. and the normal depth slope, $S_{\text {f.p. }}=0.0006$, and $S_{\text {f.p. }}<$

$S_{c 2}=0.0031<S_{m . c}$. The calculated discharge is $37.66 \mathrm{cms}$ with $7.60 \%$ increment. The sign presents the variation of velocity from positive value to negative one at the vertical dot line with significant momentum transferring along the cutting line. Of course, the difference due to energy slope will cause the stronger eddy or circulation in xy-plane. $F_{r f p}=0.2813$, $F_{r m c}=0.6954, R_{e f p}=6.420 \times 10^{5}$, and $R_{e m c}=3.1758 \times 10^{6}$.

The discharge calculation with vertical cutting sections has the increment for each case.

If the inclined cutting as Figs. (2), one main-channels with two floodplain are formed. And if we take into account the dot lines as wet perimeters, there are:

10. $\mathrm{Q}=25.0 \mathrm{cms}$ is known, $\mathrm{Zc} 2=3.03 \mathrm{~m}, U_{C L M}=4.4705 \mathrm{~m} / \mathrm{s}$, $\mathrm{d} / \mathrm{D}=0.01$. Main channel, $\overline{U_{1}}=4.1817 \mathrm{~m} / \mathrm{s}$, nm.c. $=0.014$, and floodplain, $\overline{U_{2}}=-0.2161 \mathrm{~m} / \mathrm{s}$, nf.p. $=0.016$. and the normal depth slope, $S_{m . c .}=0.0067, S_{\text {f.p. }}=-0.0014$, and $S_{\text {f.p. }}<S_{\text {m.c. }}<$ $S_{c 2}=0.0159$. The calculated discharge is $25.13 \mathrm{cms}$ with 0.52 $\%$ increment. The sign presents the variation of velocity from positive value to negative one at the inclined dot line with significant momentum transferring along the cutting line. Of course, the difference due to energy slope will cause the stronger eddy or circulation in xy-plane. $F_{r f p}=0.4302$, $F_{r m c}=0.7689, R_{e f p}=5,994$, and $R_{e m c}=2.5213 \times 10^{6}$.

11. $\mathrm{Q}=25.0 \mathrm{cms}$ known, $\mathrm{Zc} 2=3.36 \mathrm{~m}, U_{C L M}=5.2169 \mathrm{~m} / \mathrm{s}$, $\mathrm{d} / \mathrm{D}=0.11$. Main channel, $\overline{U_{1}}=3.6764 \mathrm{~m} / \mathrm{s}$, nm.c. $=0.014$, and floodplain, $\overline{U_{2}}=0.5877 \mathrm{~m} / \mathrm{s}$, nf.p. $=0.016$. and the normal depth slope, $S_{m . c .}=0.0049, \quad S_{\text {f.p. }}=0.0004$, and $S_{\text {f.p. }}<$ $S_{c 3}=0.00272<S_{m . c .}$. The calculated discharge is $26.13 \mathrm{cms}$ with $4.52 \%$ increment. The sign presents the variation of velocity from positive value to negative one at the inclined dot line with significant momentum transferring along the cutting line. Of course, the difference due to energy slope will cause the stronger eddy or circulation in xy-plane. $F_{r f p}=0.3246$, $F_{r m c}=0.6582, R_{e f p}=1.8527 \times 10^{5}$, and $R_{e m c}=2.3092 \times 10^{6}$. 12. $\mathrm{Q}=35.0 \mathrm{cms}$ is known, $\mathrm{Zc} 2=3.51 \mathrm{~m}, U_{C L M}=4.6593 \mathrm{~m} / \mathrm{s}$, $\mathrm{d} / \mathrm{D}=0.15$. Main channel, $\overline{U_{1}}=4.0806 \mathrm{~m} / \mathrm{s}$, nm.c. $=0.014$, $S_{\text {m.c. }}=0.0060$, and floodplain, $\overline{U_{2}}=1.4729 \mathrm{~m} / \mathrm{s}$, nf.p. $=0.016$. and the normal depth slope, $S_{\text {f.p. }}=0.0017$, and $S_{\text {f.p. }}<$ $S_{c 2}=0.0031<S_{m . c .}$. The calculated discharge is $36.33 \mathrm{cms}$ with $3.80 \%$ increment. The sign presents the variation of velocity from positive value to negative one at the inclined dot line with significant momentum transferring along the cutting line. Of course, the difference due to energy slope will cause the stronger eddy or circulation in xy-plane. $F_{r f p}=0.6834$, $F_{r m c}=0.7221, R_{e f p}=6.3792 \times 10^{5}$, and $R_{e m c}=2.4102 \times 10^{6}$. The discharge calculation with inclined cutting sections has the increment for each case. And we find that the errors are all smaller than the ones of the results from vertical cutting section.

\section{UNSTEADY STATE FLOW FOR THE VELOCITY PROFILE IN PRIMARY DIRECTION}

In considering the unsteady flow situation, Sine, cosine, log-Pearson III, or the two parameter gamma functions have been used as synthetic hydrographs for the upstream boundary condition of river flow computational models. Luo (2016) [11] presented a set of flood-tide hydrograph with corresponding velocity equations both flood on upstream control and tide of downstream control. These equations could be separated considering even on one side. The expressions are:

$$
\begin{aligned}
& D_{T}(x, t)=D+D_{p}\left(1-\cos \frac{2 \pi t}{T_{1}}\right)\left(1-e^{-\frac{\omega x^{\prime}}{\mu}}\right) \\
& \left(1-\operatorname{erf}\left(\frac{x}{2 \sqrt{\mu t}}\right)\right)+D_{s}\left(1-\cos \frac{2 \pi t}{T_{2}}\right) \\
& \left(e^{-\frac{\omega x^{\prime}}{\mu}}-e^{-\frac{\omega t}{\mu}}\right)\left(1-\operatorname{erf}\left(\frac{x^{\prime}}{2 \sqrt{\mu t}}\right)\right)
\end{aligned}
$$

$u_{T}(x, t)=\frac{1}{D_{T}}\left\{\left(\frac{\sqrt{\mu}}{4 \sqrt{\pi t}}\right) D_{p}\left(1-\cos \frac{2 \pi t}{T_{1}}\right)(1-\right.$

$\left.e^{-\frac{\omega x^{r}}{\mu}}\right)\left(e^{-\frac{x^{2}}{\mu t}}\right)+\frac{\omega}{8} D_{p}(1$

$\left.\cos \frac{2 \pi t}{T_{1}}\right)\left(e^{-\frac{4 l \omega t-\omega^{2} t^{2}}{4 \mu t}}\right)\left[\operatorname{erf}\left(\frac{2 l-x}{2 \sqrt{\mu t}}\right)+\operatorname{erf}\left(\frac{x}{2 \sqrt{\mu t}}\right)\right]-$

$\left(\frac{2 \pi D_{p}}{T_{1}}\right) \sin \left(\frac{2 \pi t}{T_{1}}\right)\left[x\left(1+\frac{\sqrt{\mu} e^{-\frac{\omega x^{\prime}}{\mu}}}{\omega \sqrt{\pi t}}\right)-\frac{x^{2}}{2 \sqrt{\pi \mu t}}-\right.$

$\left.\left(\frac{\mu}{\omega}\right)\left(e^{-\frac{\omega x^{\prime}}{\mu}}\right)\left(1+\frac{\mu}{\omega \sqrt{\pi \mu t}}\right)\right]-\left(\frac{\sqrt{\mu}}{4 \sqrt{\pi t}}\right) D_{s}(1-$

$\left.\cos \frac{2 \pi t}{T_{2}}\right)\left(e^{-\frac{\omega x^{\prime}}{\mu}}-e^{-\frac{\omega t}{\mu}}\right)\left(e^{-\frac{x^{\prime 2}}{\mu t}}\right)-\frac{\omega}{8} D_{s}(1-$

$\left.\cos \frac{2 \pi t}{T_{2}}\right)\left(e^{-\frac{4 l \omega t-\omega^{2} t^{2}}{4 \mu t}}\right)\left[\operatorname{erf}\left(\frac{2 l+x^{\prime}}{2 \sqrt{\mu t}}\right)-\operatorname{erf}\left(\frac{x^{\prime}}{2 \sqrt{\mu t}}\right)\right]+$

$\left.\left(\frac{2 \pi D_{s}}{T_{2}}\right) \sin \left(\frac{2 \pi t}{T_{2}}\right)\right\}\left\{\left(x^{\prime}\right)^{2}\left(\frac{1}{2 \sqrt{\pi \mu t}}\right) e^{-\frac{\omega t}{\mu}}+\right.$

$\left(x^{\prime}\right)\left(\frac{\mu}{2 \sqrt{\pi \mu t}}\right)\left(e^{-\frac{\omega x^{\prime}}{\mu}}-e^{-\frac{\omega t}{\mu}}\right)-\left(\frac{\mu}{\omega}\right)\left(e^{-\frac{\omega x^{\prime}}{\mu}}\right)\left(\frac{\mu}{\omega \sqrt{\pi \mu t}}-\right.$

1) $\}+u_{0}$ 


\section{ISSN: 2277-3754 \\ ISO 9001:2008 Certified \\ International Journal of Engineering and Innovative Technology (IJEIT) \\ Volume 11, Issue 2, August 2021}

$l$ is the length of the channel reach.

$\mathrm{x}=$ distance along the channel, counting from upstream.

$x=l-\mathrm{x}$

$\mu$ : a wave dispersion coefficient.

$\omega=\frac{3}{2} u_{0}=$ wave velocity

$u_{0}=C_{c}\left[\left(H_{0}+h_{0}\right) S_{0}\right]^{1 / 2}$

$C_{c}$ : Chezy roughness coefficient

$h_{0}$ or D : the average height of the water level above $H_{0}$ $S_{0}$ : bed slope

$\mu$ : a wave dispersion coefficient $=\frac{q_{0}}{2 s_{0}}\left(1-F_{0}^{2}\right)$

$q_{0}$ : unit-width discharge of steady state boundry condition

$F_{0}$ : Froude number of steady state boundry condition

$H_{0}$ : The wave amplitude

T: hydrograph cycle. 1 for upstream and 2 for downstream t: time

$D_{p}$ : amplitude of hydrograph cycle for flood of upstream.

$D_{s}$ : amplitude of hydrograph cycle for tide of downstream.

By combing Eqs. (34) and (46), the full form of 3D unsteady state flow velocity profile is obtained.

\section{DISCUSSION AND CONCLUSIONS}

Flow issues due to open channels. Determining the critical depths of canals and natural streams of various shapes is a traditional task, but it is vital for effective hydraulic design. Critical depth is commonly used to classify flows as subcritical or supercritical, and it can also be utilised as a control point for computing water surface profiles in steady and unstable gradually varying flows.

Since the main channel and the flood plains have different hydraulic qualities, such as flow depth and resistance, as well as cross-section shape, flow hydraulics in these parts is extremely complicated. Movement between flood plains and the main channel must be taken into account when calculating hydraulic parameter distribution. Three different flow regimes can exist in compound channels: fully subcritical, fully supercritical, and a mixed flow regime. The whole of compound cross section does not behave as a control section, except in the higher relative

depth, such as Dr>0.5. Turbulence due to secondary flow terms, because of roughness ratio and the geometrical effects from the main-channel width ratio and the abruptly expanded cross-section area just bankful, can be generated considerable error for prediction of lateral distribution of hydraulic characteristics.

1. From Eq. (1) to Eq. (31), we have the mean phenomema and results of the multiple critical depths for the compound channel for given discharges. The corresponding water syrface profiles are also expressed between or among these critical energy slope and if the bed slope respectively the mean velocity of the compound channel cross-section, is known, the flow situations will be clearly presented. Meanwhile the multiple critical depths for the compound channel for given discharges should be avoided when you design your hydraulic structures.

2. Based on Eqs. (32) to (40), the result of mean velocity for the compound channel cross-section is derived and which is used to calculate the mean velocities for the horizontal cutting sub-cross-section with the given discharge. Then the corresponding energy slopes for the resultant normal depth and velocity are calculated on main-channel and floodplain respectively. The comparisons between normal depth energy slopes and the corresponging critical depth energy are worked. The eddy or circulation will happens for the situation of the discharge giving the water depth just bankful the main-channel due to the inverse flow velocity directions, which has strong momentum transferring. Therefore, the virtual separation line is necessary to take into account as the wet perimeter to recalculate the hydraulic characteristics. 3. Assuming the hydraulic results of flow velocities on the horizontal virtual separison method with the corresponding discharge, Manning coefficients, and taking into account the virtual separation boundries as the wet perimeters are accepted, we calculate the corresponging normal depth energy slopes for each situation on separatly the vertical and inclined virtual separation sub-sections. The comparisons on energy slopes and discharges have been fulfilled. The momentum transferring still exist at the virtual separation boundaries, and the smaller errors of discharges happen on the inclined virtual separation cases that the errors almost just half of the corresponding vertical virtual separation cases. Here, the corresponding Froude number and Reynold number for each subsection also can be calculated. Because the Froude nember has nothing to do with the perimeters, the results for whether hydraulic radius is the same or not, but the Reynold number will be different for the perimeter variation due to $R_{e}=\bar{U} R / \nu$ with $\mathrm{R}=\mathrm{A} / \mathrm{P}=\left(\bar{U} \mathrm{n} / S^{1 / 2}\right)^{3 / 2}$.

4. Combining the synthetic hydrographs for the upstream boundary condition of river flow, the $3 \mathrm{D}$ unsteady state flow situation could be obtain, even the tidal effect is taken into account.

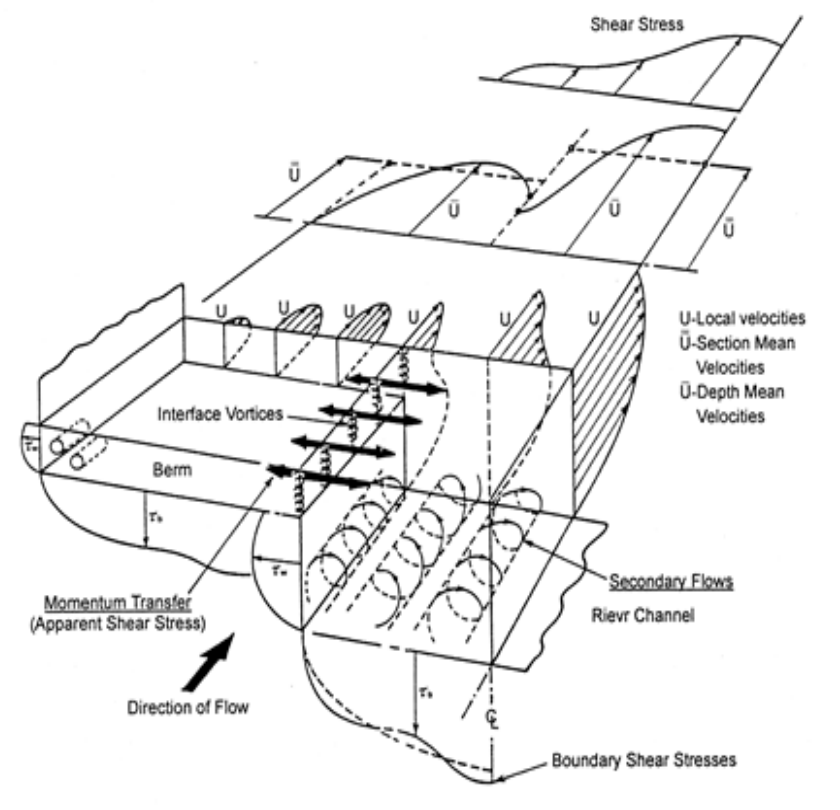

Fig. 1. Scheme of Compound Channel 
ISSN: 2277-3754

ISO 9001:2008 Certified

International Journal of Engineering and Innovative Technology (IJEIT)

Volume 11, Issue 2, August 2021

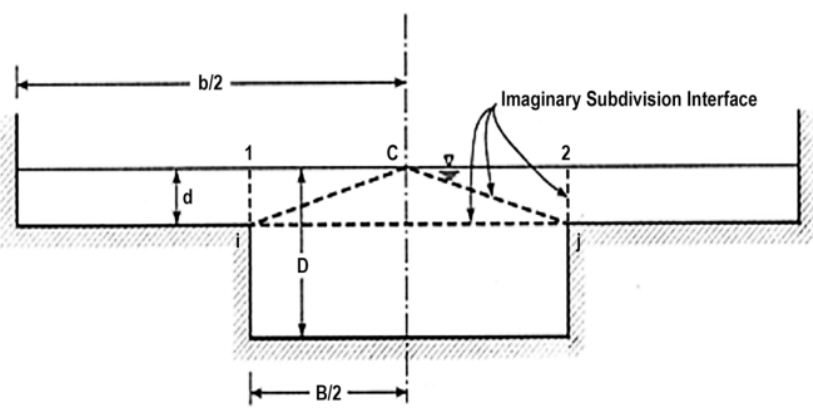

Fig. 2. Definitions of the Cross-Section of Compound Channel
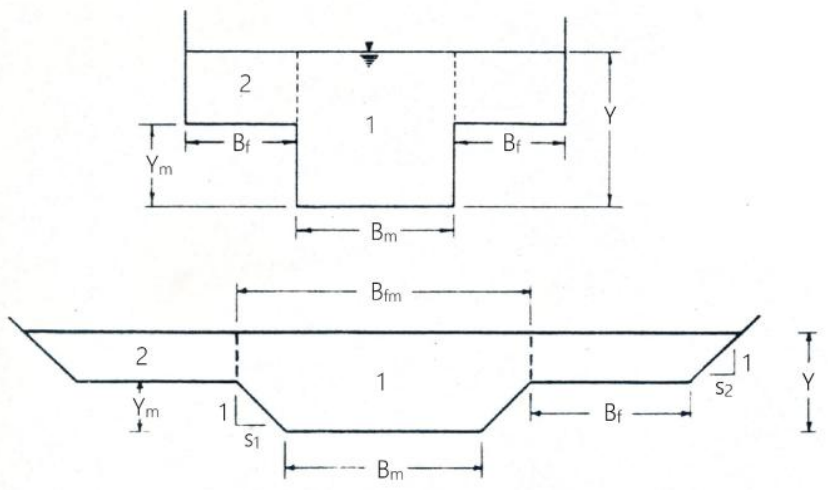

Fig. 3. Compound channel cross-sections:

(a) Rectangular cross-section; (b) Trapezoid cross-section B.

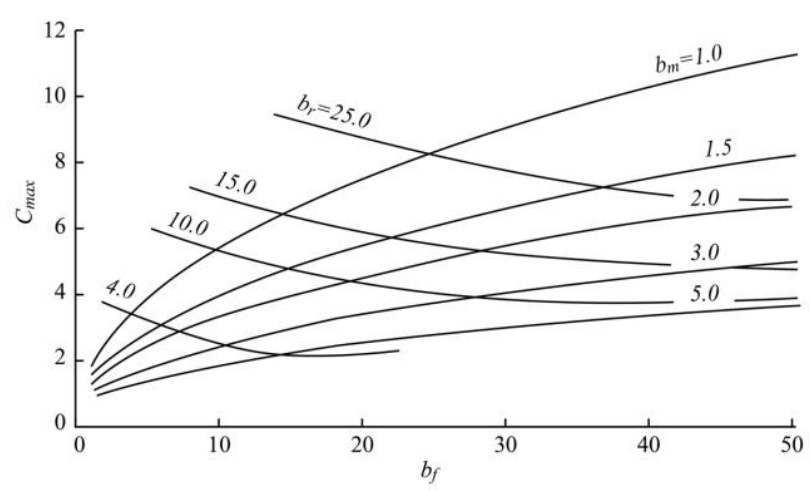

Fig. 4 The relationship between Cmax and bf for the given roughness ratio the variation

of br and bm

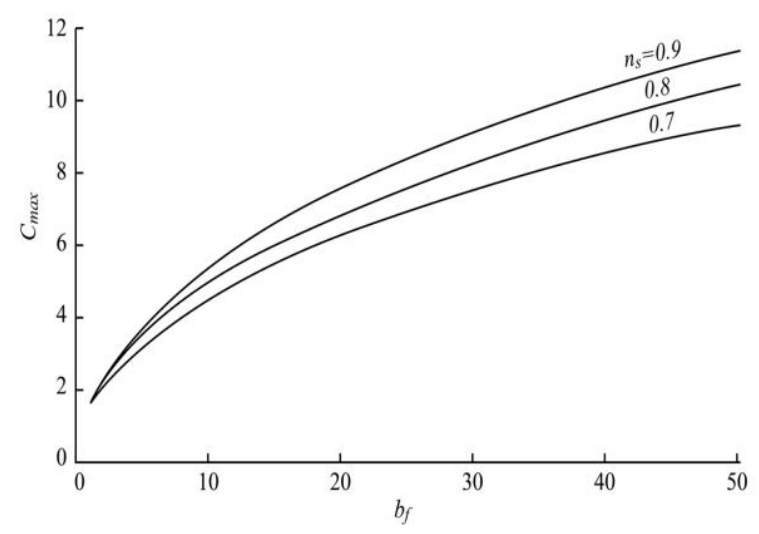

Fig. 5 The relationship between Cmax and bf for the give given width ratio with the variation of roughness ratio

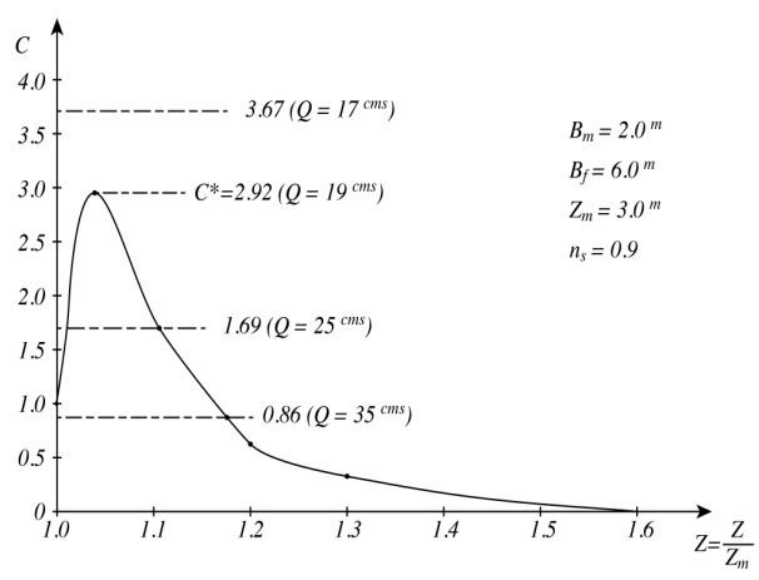

Fig. 6. C-z Curve

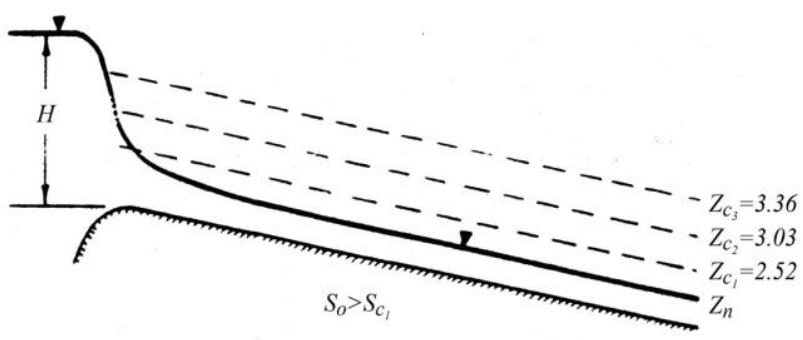

(a)

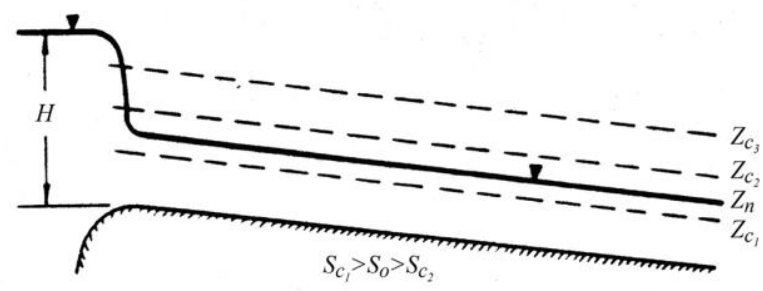

(b)

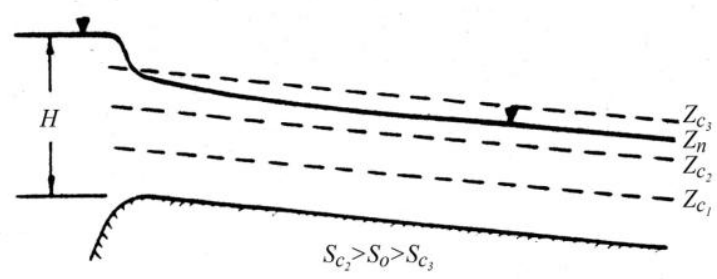

(c)

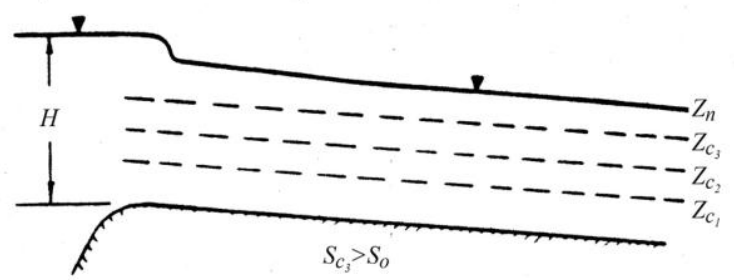

(d)

Fig. 7 The water surface profile for the normal depth and critical depth, corresponding to the bed slope and critical slope 
ISSN: 2277-3754

ISO 9001:2008 Certified

International Journal of Engineering and Innovative Technology (IJEIT)

Volume 11, Issue 2, August 2021

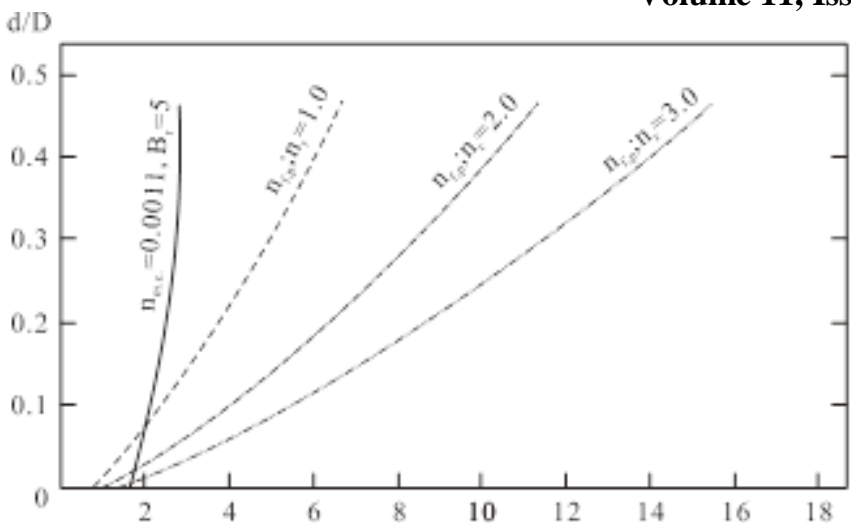

Fig. 8. The relationship between depth averaged turbulent viscosity and the depth ratio at the intersection surface for different roughness ratio

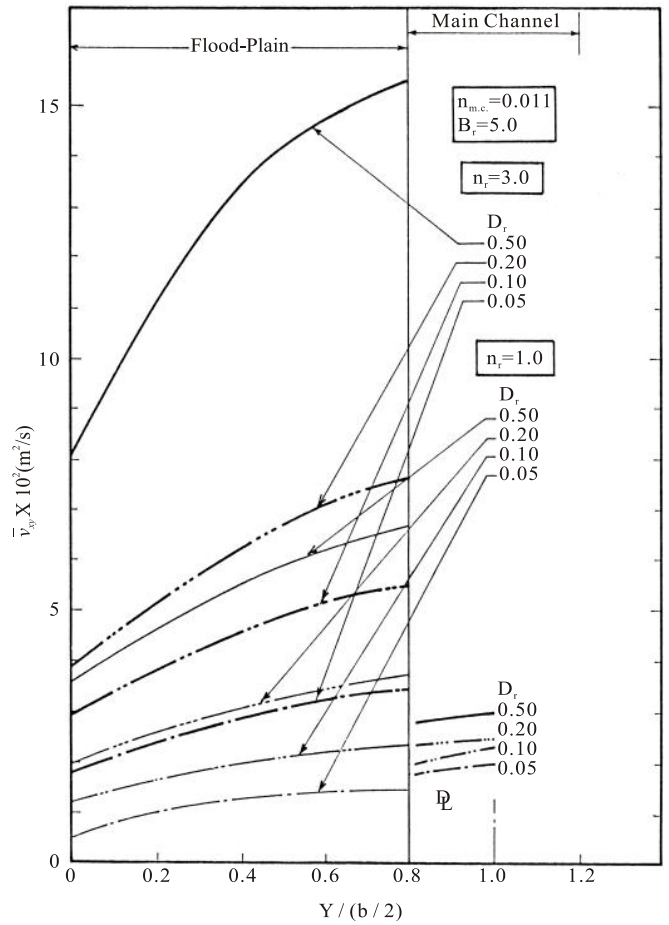

Fig. 9. The distribution of depth - averaged turbulent viscosity along the cross - section for different depth - ration and roughness - ratio

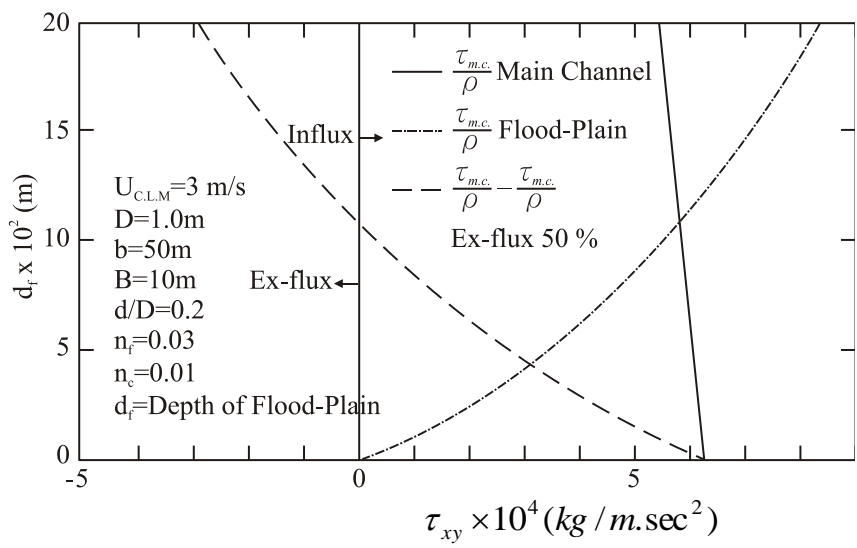

Fig. 10. The apparent shear stresses at the edge of intersection above bankful of main channel, $\mathrm{d} / \mathrm{D}=\mathbf{0 . 2}$

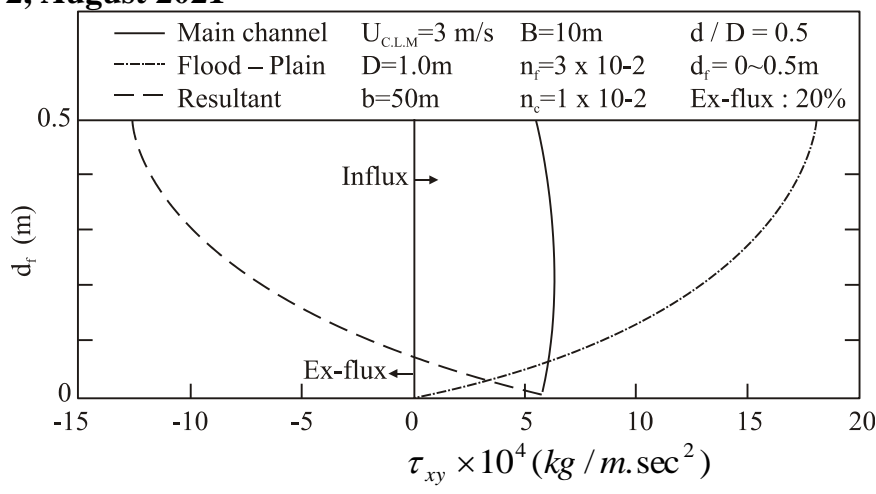

Fig. 11. The apparent shear stresses at the edge of intersection above bankful of main channel, $\mathrm{d} / \mathrm{D}=\mathbf{0 . 5}$

\section{REFERENCES}

[1] Blalock, M.E. and Sturm, T.W.,"Minimum specific energy in compound channel", ASCE, J. Hydraulics Division. Vol. 107,1981,pp.: 699-717.

[2] Konemann, N., "Discussion of "Minimum Specific Energy in Compound Open Channel", ASCE, J. Hydraulics Division, Vol. 108, 1982, pp:462-464.

[3] Edward C. R. Luo, "Hydrodynamic Characteristics in Non-uniform Channel", Dissertation of Doctor, Asian Institute of Technology, Diss. No. WA 93-1,1993,pp:1-76.

[4] Petrik, S. and Grant, E.U., "Critical flow in rivers with flood plains", ASCE, J. Hydraulics Division, Vol. 104, 1978, pp.583-594.

[5] Schoellhamer, D.H., Peters, J.C. and Larock, B.E., "Subdivision Froude number", ASCE, J. Hydraulic Engineering, Vol. 111, 11985, pp.1099-1104.

[6] Soil Conservation Service, WSP-2 Computer program, a water surface profile computer program for determining flood elevations and flood areas for certain flow rates, Technical release No.61,1976.

[7] Sturm, T.W., Skolds, D. M., and Blalock, M. E., "Water surface profile in compound channels, Hydraulics and Hydrology in Small Computer Age", Vol. 1, Proceedings of the Speciality Conference sponsored by Hydraulics Division of the ASCE, Lake Buena Vista, Florida,1985, pp.569-574.

[8] United States Army Corps of Engineers, "HEC-2: Water surface profile user manual, Hydrologic Engineering Center",1982,pp:1-390.

[9] United States Geological Survey,"Computer applications for step-backwater and floodway analysis",USGS open file report 76-499,1976, pp:1-108.

[10] Luo Ching-Ruey (Edward), "Apparent shear stress in symmetric-straight compound-channel flow", IJEP Vol.1 No. 2, 2011,pp.:28-32.

[11] Luo Ching-Ruey (Edward), "Loop rating curve of tidal river: flood and tide interaction", International Journal of Engineering and Advanced Technology Studies, Vol.4, No.5, 2016, pp.13-72. 
ISSN: 2277-3754

ISO 9001:2008 Certified

International Journal of Engineering and Innovative Technology (IJEIT)

Volume 11, Issue 2, August 2021

\section{AUTHOR BIOGRAPHY}

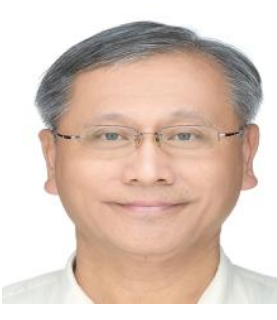

LUO Ching-Ruey (Edward) was born on 21, March 1957 in Taiwan. He has $\mathrm{PhD}$ degree in Business Administration Management, (PALLADIUM University, PALLAMA, 2004-2007) with major in Conflict and Strategic Management; PhD in Psychology (University of Central Nicaragua, NICARAGUA) with major in Theory and Practice on Psychotherapy and Counseling (2004-2007) and $\mathrm{PhD}$ in Hydrodynamics Engineering (1990-1993, Asian Institute of Technology, Thailand) with Major in River, Estuary, Marine, Ecological Engineering, and Debris Flow Engineering.

He has the following professional memberships as follow:2007 to now: Deputy Director General (DDG) of International Biographical Centre (IBC), Cambridge, England;2006 to now: Committee Member on Research and Development of American Biographical Institute (ABI) U.S.A; Certified Licenses: EMF, International Engineers (Hydraulic Engineering); Asia-Pacific Engineers(Hydraulic Engineering); Senior Professional Hydraulic Engineer (P.E.), Taiwan; Arbitration Member, Taiwan.

\section{Job Experience:}

Jan. 2010 and continue, Chief Engineer of Hunghua

Construction Co., Ltd. Taichung, Taiwan

Jan. 2001 and continue, Part-time Assistant Professor of

National Chi Nan University, Nantou, Taiwan.

Sep.2010 to Aug.2013, Part-time Professor of Palladium

University

Sep.2010 to Aug.2013, Part-time Professor of Southern

Christian University

Sep.2010 to Aug.2013, Part-time Professor of University

Central of Nicaragua

July 1997 to 2009, Chief Engineer, Hsing-Nan -Lung

Construction Company

Jan. 2000 to Dec. 2006, President of Ching-Chan Eng. Ltd

Feb. 1994 to June 1995, Researcher, ITR

March 1984 to Dec. 1986, Advanced Engineer, WRB, MOE.

Aug. 1979 to Feb. 1984, Basic Engineer, WRB, MOE

\section{Certified Licenses:}

IPE, International Engineers (Hydraulic Engineering)

Asia-Pacific Engineers (Hydraulic Engineering)

Senior Professional Hydraulic Engineer (P.E.), Taiwan

Arbitration Member, Taiwan

Member on Quality Control, Taiwan

Senior Counselor in China, PRC

Senior Health Management Division in China, PRC

Senior Hydraulic Engineer in China, PRC

Senior Architect Engineer in China, PRC

Senior Municipal Utility Engineer in China, PRC

Senior Cost Analysis Engineer in China, PRC 